\title{
Insurance Marketing Channel as a Screening Mechanism: Empirical Evidences from Taiwan Automobile Insurance Market
}

\author{
Shu-Hui Hsieh ${ }^{\mathrm{a}, \mathrm{b}}$, Chun-Ting Liu ${ }^{\mathrm{a}}$ and Larry Y. Tzeng ${ }^{\mathrm{c}}$ \\ a Department of Insurance and Finance, National Taichung University of Science and Technology, 129 Sec. \\ 3, San-min Rd., Taichung, Taiwan. \\ E-mails: shshei@nutc.edu.tw; madux@nutc.edu.tw \\ ${ }^{\mathrm{b}}$ College of Business, Feng Chia University, No. 100, Wenhwa Rd., Taichung 407, Taiwan. \\ ${ }^{c}$ Department of Finance, National Taiwan University, Room 709, Management Hall II 50, Lane 144, \\ Keelung Rd, Sec 4, Taipei 106, Taiwan. \\ E-mail: tzeng@ntu.edu.tw
}

Venezia, Galai and Shapira in 1999 proposed a theoretical framework that considers asymmetric information to explain the co-existence of the independent agent and direct underwriting systems in the insurance market. In separating equilibrium, high-risk clients tend to purchase insurance through independent agents, whereas low-risk clients prefer dealing directly with underwriters. Using a unique data set from Taiwan's automobile liability insurance, this paper tests the screening mechanism hypothesis proposed by Venezia, Galai and Shapira. The results reveal that a positive channel-claim correlation exists in the subsamples of cars aged more than three years. Significant positive channel-claim correlation indicates that high-risk policyholders prefer to purchase insurance from an independent agent, whereas those with lower risks tend to buy insurance from direct writer channels. The results support the screening mechanism hypothesis and demonstrate that marketing channel choice could serve as a screening mechanism in an insurance market characterised by asymmetric information.

The Geneva Papers (2014) 39, 90-103. doi:10.1057/gpp.2012.52

Keywords: asymmetric information; independent agent system; direct underwriting system; screening mechanism hypothesis

Article submitted 19 May 2011; accepted 29 October 2012; published online 23 January 2013

\section{Introduction}

The choice of a marketing channel is one of the most crucial business decisions for insurance executives. Two types of marketing channels prevail in the insurance market: the exclusive agent or the direct underwriting system, and the independent agent system. ${ }^{1}$ An exclusive agent, or a direct underwriter, is bound to one

\footnotetext{
${ }^{1}$ Independent agents and brokers are responsible for generating nearly US\$6 of every US\$10 in the U.S. insurance industry's overall property-casualty premium revenue. They produced US\$288.5 billion of the total US\$489 billion market in 2007 (compared with US\$289.3 billion in 2006, US\$284.1 billion in 2005 and US\$276.11 billion in 2004).
} 
insurer, whereas an independent agent can sell insurance policies to several insurers.

The choice of a marketing channel has received in-depth attention in the literature. Several studies ${ }^{2}$ have investigated the relationship between the insurer and the agents, whereas other studies ${ }^{3}$ have examined the relationship between the insured and the agent. Two types of hypotheses are proposed in the literature to support the coexistence of independent and exclusive agents (or direct underwriters) and they are the product quality and the market imperfection hypotheses.

The product quality hypothesis asserts that two distribution systems co-exist in the market because independent agents provide higher service intensity, but with higher costs than exclusive agents. ${ }^{4}$ The market imperfection hypothesis suggests two distribution systems co-exist in the market because of asymmetric information. Venezia et al. ${ }^{5}$ provide a theoretical framework of asymmetric information to explain the co-existence of direct underwriters and independent agents. Their study also predicts that low-risk clients will choose to purchase insurance through direct underwriters during equilibrium, whereas high-risk clients will prefer to deal with independent agents.

Several papers provide empirical evidence supporting the product quality hypothesis. ${ }^{6}$ However, relatively few papers provide empirical evidence to examine the market imperfection hypothesis. The current paper intends to fill this gap by investigating the predictions proposed by Venezia et al. ${ }^{5}$ Moreover, this paper contributes to existing literature by taking a different angle of empirical evidence on the existence of asymmetric information in the insurance market. Several papers found no evidence ${ }^{7}$ supporting the existence of asymmetric information in the insurance market, but other papers $^{8}$ provide a number of evidence supporting it. Most of these papers examine the problem by testing the relationship between the choice of coverage and the occurrence of risk. Unlike those papers, the current study intends to test the choice of marketing channel and the occurrence of risk.

The present study used a unique data set of a large insurer's automobile insurance holders in Taiwan in 2008. ${ }^{9}$ Insurance policies were distributed through the independent agencies (brokerage firms) and direct underwriting systems. In Taiwan's automobile

2 Joskow (1973); Cummins (1977); Cummins and VanDerhei (1979); Mayers and Smith (1981); Marvel (1982); Sass and Gisser (1989); Barrese and Nelson (1992); Blair and Herndon (1994); Kim et al. (1996); Regan and Tennyson (1996); Regan (1997); Berger et al. (1997); Regan and Tzeng (1999); Klumpes (2004); Klumpes and Schuermann (2011).

${ }^{3}$ Posey and Yavas (1995); Kim et al. (1996); Berger et al. (1997); Posey and Tennyson (1998); Seog (1999); Venezia et al. (1999); Trigo-Gamarra (2008).

${ }^{4}$ Etgar (1976); Barrese and Nelson (1992); Barrese et al. (1995); Kim et al. (1996); Berger et al. (1997); Trigo-Gamarra (2008).

${ }^{5}$ Venezia et al. (1999).

${ }^{6}$ Barrese and Nelson (1992); Barrese et al. (1995); Kim et al. (1996); Berger et al. (1997); Trigo-Gamarra (2008).

${ }^{7}$ Cawley and Philipson (1999); Chiappori and Salanie (2000); Dionne et al. (2001); Saito (2006).

${ }^{8}$ Browne (1992); Browne and Doerpinghaus (1993); Puelz and Snow (1994); Dionne and Gagne (2002); Fong (2002); Finkelstein and Poterba (2004); Finkelstein and McGarry (2006); Li et al. (2007); Wang et al. (2008); and Kim et al. (2009); Haddad and Anbaji (2010).

${ }^{9} \mathrm{We}$ also used the 2006 and 2007 data sets to test the screening mechanism hypothesis and to obtain consistent results. 
insurance market, the Insurance Bureau of the Financial Supervisory Commission permits insurers to offer a reasonable discount on premium if customers purchase the insurance through the direct underwriting system. Conversely, independent agents could provide better ex-ante risk analysis and ex-post claim coordination services instead of price discounts and negotiations. Therefore, considering the claim service, high-risk customers are more likely to purchase expensive insurance offered by independent agents, whereas low-risk customers tend to choose inexpensive insurance from direct underwriters. This situation presents a unique opportunity to examine the asymmetric information between the level of risk presented by policyholders and the choice of marketing channel.

This paper employs two-stage regressions commonly used to test asymmetric information. Customers were categorised as policyholders with cars aged three years or less and policyholders with cars aged more than three years. The empirical models found that a positive channel-claim correlation only exists in the subsamples of owners with cars aged more than three years. The channel and the risks are not positively correlated to the subsamples of owners of cars aged three years or less probably because most new car buyers decide to purchase insurance from a dealerowned agent. Thus, the dealer-owned agent has both high and low-risk clients. Therefore, the findings in the subsamples of owners of cars aged three years or less reflect that newer car owners mostly rely on dealer-owned agents.

Moreover, the channel is positively correlated with risks for subsamples with owners of cars aged more than three years. This observation indicates that policyholders who acquire high risks prefer to purchase insurance from an independent agent, whereas those with lower risks tend to buy insurance from the direct writer. These findings contribute to the literature in two ways. First, we find new empirical support for the existence of asymmetric information in the insurance market. Second, the results support the screening mechanism hypothesis proposed by Venezia et al., and demonstrate that the marketing channel may serve as a screening mechanism in an insurance market under asymmetric information.

The remainder of this article is organised as follows. The next section provides an introduction to the automobile insurance market and marketing channels of Taiwan. The subsequent sections describe the data set and the proposed empirical procedures. The penultimate section reports on the estimation results. The final section concludes the paper.

\section{Automobile insurance and marketing channels in Taiwan}

In Taiwan's automobile insurance market, approximately 5.49 million car owners purchase automobile insurance from 22 property and liability insurance companies. In 2008, automobile insurance accounted for about 48.77 per cent of premiums for property and liability insurance. In the same year, the annual premiums for automobile insurance reached US\$1,768 million.

Two major types of marketing channels co-exist in the market, namely independent agencies and direct underwriting systems. Independent agents include dealer-owned, bank assurance and brokers. The amount of automobile insurance premiums sold 
through the independent agency system was approximately US\$724 million in 2008, which reflected a 40.98 per cent market share. The direct underwriting system allows customers to purchase insurance from insurers who operate through mail and Internet marketing, or through a salaried-employee system. The total amount of premiums sold through the direct underwriting system was approximately US $\$ 1.043$ billion in 2008 , which accounted for 59.02 per cent of the market.

The major differences between the two marketing channels are price and product/ service. First, the Insurance Bureau of the Financial Supervisory Commission in Taiwan allows insurers to charge different prices through a discount system if customers purchase insurance through the direct underwriting system. No discount is offered when customers deal with independent agents regarding their insurance requirements. Second, independent agents may represent more expensive insurance channels; hence, the quality of service they provide may be superior to that offered by direct underwriters. This assumption is based on Mayers and Smith, Barrese et al., Kim et al. and Berger et al., ${ }^{10}$ who argue that independent agents are more effective in representing the interests of their clients because they obtain claim service information from cooperative insurers. Therefore, these agents can provide better ex-ante insurance claim consultation services to various customers.

In addition, independent agents own the policyholder list; hence, they can negotiate a claim more convincingly or take their customers to an alternative insurer if the claims of the customers are not satisfied. ${ }^{11}$ Thus, independent agents can offer customers better claim coordination than direct underwriters can offer. Therefore, in view of the claim service, high-risk customers are more likely to purchase expensive insurance through independent agents, whereas low-risk customers tend to choose inexpensive insurance from direct underwriters. Taiwan's automobile insurance market presents a unique opportunity to examine the channel-risk correlation amid asymmetric information problems.

This paper focuses on the analysis of automobile third-party liability insurance. In cases of automobile third-party liability insurance in which the insured negotiates with a third party, the focus is typically placed on matters such as identification of fault liability and claim amounts. For example, when a third party is physically injured or when a significant disagreement exists between parties in an accident, the policyholder negotiates with the third party, and the independent agent mediates and demands that the insurer properly addresses the compensation case. The independent agent can also demand flexible compensation from the insurer to hasten the settlement process between the concerned parties. Such ex-post claim coordination services that are necessary after an accident prove to be exceedingly important in automobile third-party liability insurance. Independent agents find it easier to highlight advantageous claim services for voluntary third-party liability insurance. Thus, compared with customers who purchase compulsory liability insurance solely, customers who purchase additional voluntary third-party insurance have high demands for advantageous claim services from independent agents. Therefore, voluntary automobile third-party liability insurance is selected in testing the screening mechanism hypothesis.

\footnotetext{
${ }^{10}$ Mayers and Smith (1981); Barrese et al. (1995); Kim et al. (1996), Berger et al. (1997).

${ }^{11}$ Berger et al. (1997); Venezia et al. (1999); Trigo-Gamarra (2008).
} 


\section{Data and variables}

In this study, voluntary automobile third-party liability insurance data are compiled. The data are obtained from a large property and casualty insurance company in Taiwan. The data set includes information on 198,292 voluntary third-party liability insurance policyholders who joined the insurer in 2008. Our data include a complete set of information that the insurance company collected for each contract, which covers details about the choice of marketing channel, claim records, risk classification and bonus-malus coefficient. Therefore, the data set consists of all observable variables that the insurer offers on each contract, making it easy to control potential deceptiveness in the conditional correlation between the marketing channel choice and the accident claims. For each contract, 15 variables are tracked, including the policyholder's choice of marketing channel, claim records, risk classification, bonusmalus coefficient, car age and premium discount variables. ${ }^{12}$ The definitions of variables are presented in Table 1 .

When testing the channel risk correlation, the endogeneity problem should be noted because coverage could be affected by risk, which, in turn, could affect the choice of coverage. Therefore, we restrict our sample in the following way. Third-party liability insurance in Taiwan provides a single and fixed coverage amount for a policyholder's bodily injury and property damage protection. Specifically, six different amount levels are included in the bodily injury coverage, which are NT\$0.5, 1, 1.5, 2, 2.5 and 3 million. Under property damage protection, six different levels of coverage are available, which are NT\$0.1, 0.2, 0.3, 0.4, 0.5 and 1 million. In our sample, approximately 50 per cent of the policyholders chose the combination of NT\$2 million for bodily injury coverage, and NT $\$ 0.5$ million for property damage coverage protection. Thus, we focus on this specific type of insurance coverage to test the correlation between risk and marketing channel choice. Our final sample consists of 104,191 policyholders.

As most papers indicate, a claim is used as a proxy for an accident. Although the current paper lacks a suitable accident variable, ${ }^{13}$ the "accident $\neq$ claim" problem may not cause potential biases. Under Taiwan's bonus-malus system, an application for a claim settlement increases the premium in the following policy year by 30 per cent. For most policyholders, accident-causing costs are approximately from NT\$1200 to 2400 (with the premium between NT\$4000 and 8000). ${ }^{14}$ Thus, for voluntary automobile third-party liability insurance, the benefits of applying for claim settlements will be higher than accident-causing costs in most cases. Although loss amounts will be lesser than the accident-causing costs that will render the policyholder unable to apply for

12 The bonus-malus coefficient depends on the policyholder's claim records of the past three years. To include completely the coefficient as a dummy for each bonus-malus category, we designed five bonusmalus categories corresponding to the past claim records of three years, which are equal to $0,1,2,3,4$ and over 4 times.

${ }^{13}$ The "accident $\neq$ claim" problem always matters as long as the claim data come from an insurance company.

14 The accident-causing costs are approximately US\$ 40-80 (with the premium between NT\$134 and NT\$268). 
Table 1 The definition of variables

\begin{tabular}{ll}
\hline Dependent variables & Definition \\
\hline Channel & $\begin{array}{l}\text { A dummy variable equals } 1 \text { if the policyholder chose an independent agent or } \\
\text { broker for his/her auto liability insurance needs; } 0 \text { otherwise }\end{array}$ \\
Claim & $\begin{array}{l}\text { A dummy variable equals } 1 \text { if the policyholder filed at least an accident insurance } \\
\text { claim either in the compulsory insurance or in the voluntary third-party liability } \\
\text { insurance in the current policy year; } 0, \text { otherwise. }\end{array}$
\end{tabular}

Initial exogenous variables $\left(X_{i}\right)$

Pricing factors

Class_1

Class_2

Class_3

Class_4

Class_5

Class_6

Class_7

Class_8 (reference group)

Class_9

Class_10

B_M_Dummy_0 (reference group)

B_M_Dummy_1

B_M_Dummy_2

B_M_Dummy_3

B_M_Dummy_4

Additional variables

Car age

Premium discount
Definition

A dummy variable equals 1 if the policyholder is male and age is between 18 and 19 years; 0 otherwise.

A dummy variable equals 1 if the policyholder is female and age is between 18 and 19 years; 0 otherwise.

A dummy variable equals 1 if the policyholder is male and age is between 20 and 24 years; 0 otherwise.

A dummy variable equals 1 if the policyholder is female and age is between 20 and 24 years; 0 otherwise.

A dummy variable equals 1 if the policyholder is male and age is between 25 and 29 years; 0 otherwise.

A dummy variable equals 1 if the policyholder is female and age is between 25 and 29 years; 0 otherwise.

A dummy variable equals 1 if the policyholder is male and age is between 30 and 59 years; 0 otherwise.

A dummy variable equals 1 if the policyholder is female and age is between 30 and 59 years; 0 otherwise.

A dummy variable equals 1 if the policyholder is male and age is over 60 years old; 0 otherwise.

A dummy variable equals 1 if the policyholder is female and age is over 60 years old; 0 otherwise.

A dummy variable equals 1 if the policyholder did not file any accident insurance claim in the past three years; 0 otherwise.

A dummy variable equals 1 if the policyholder filed one accident insurance claim in the past three years; 0 otherwise.

A dummy variable equals 1 if the policyholder filed two accident insurance claims in the past three years; 0 otherwise.

A dummy variable equals 1 if the policyholder filed three accident insurance claims in the past three years; 0 otherwise.

A dummy variable equals 1 if the policyholder applied at least four accident insurance claims in the past three years; 0 otherwise.

\section{Definition}

The insured car age

A dummy variable equals 1 if the policy has a discount on premium; 0 otherwise. 
Table 2 The mean analysis of variables in different marketing channels

\begin{tabular}{|c|c|c|c|c|c|c|c|c|c|}
\hline \multirow[t]{2}{*}{ Variables } & \multicolumn{3}{|c|}{ Total samples } & \multicolumn{3}{|c|}{ Car age $\leqslant 3$ years } & \multicolumn{3}{|c|}{ Car age $>3$ years } \\
\hline & $\begin{array}{c}\text { Total } \\
\text { samples }\end{array}$ & $\begin{array}{c}\text { Independent } \\
\text { agent }\end{array}$ & $\begin{array}{c}\text { Direct } \\
\text { underwriter }\end{array}$ & $\begin{array}{c}\text { Total } \\
\text { samples }\end{array}$ & $\begin{array}{l}\text { Independent } \\
\text { agent }\end{array}$ & $\begin{array}{c}\text { Direct } \\
\text { underwriter }\end{array}$ & $\begin{array}{c}\text { Total } \\
\text { samples }\end{array}$ & $\begin{array}{l}\text { Independent } \\
\text { agent }\end{array}$ & $\begin{array}{c}\text { Direct } \\
\text { underwriter }\end{array}$ \\
\hline Channel & 0.7442 & - & - & 0.8801 & - & - & 0.6651 & - & - \\
\hline Claim & 0.0518 & 0.0537 & 0.0465 & 0.0522 & 0.0524 & 0.0503 & 0.0516 & 0.0546 & 0.0457 \\
\hline $\begin{array}{l}\text { Claim } \\
\text { number }\end{array}$ & 0.0594 & 0.0610 & 0.0546 & 0.0628 & 0.0625 & 0.0531 & 0.0574 & 0.0598 & 0.0525 \\
\hline Class_1 & 0.0000 & 0.0000 & 0.0000 & 0.0000 & 0.0000 & 0.0002 & 0.0000 & 0.0001 & 0.0000 \\
\hline Class_2 & 0.0000 & 0.0001 & 0.0000 & 0.0001 & 0.0001 & 0.0000 & 0.0000 & 0.0000 & 0.0000 \\
\hline Class_3 & 0.0024 & 0.0024 & 0.0022 & 0.0043 & 0.0042 & 0.0050 & 0.0012 & 0.0011 & 0.0016 \\
\hline Class_4 & 0.0026 & 0.0025 & 0.0026 & 0.0039 & 0.0038 & 0.0046 & 0.0018 & 0.0016 & 0.0022 \\
\hline Class_5 & 0.0222 & 0.0229 & 0.0204 & 0.0343 & 0.0347 & 0.0314 & 0.0153 & 0.0138 & 0.0182 \\
\hline Class_6 & 0.0199 & 0.0200 & 0.0196 & 0.0298 & 0.0293 & 0.0333 & 0.0141 & 0.0128 & 0.0168 \\
\hline Class_7 & 0.5696 & 0.5824 & 0.5326 & 0.5893 & 0.5889 & 0.5927 & 0.5582 & 0.5774 & 0.5201 \\
\hline Class_9 & 0.0327 & 0.0296 & 0.0417 & 0.0208 & 0.0201 & 0.0257 & 0.0397 & 0.0370 & 0.0450 \\
\hline Class_10 & 0.0267 & 0.0256 & 0.0301 & 0.0223 & 0.0229 & 0.0174 & 0.0294 & 0.0276 & 0.0328 \\
\hline B_M_1 & 0.1885 & 0.2237 & 0.0858 & 0.3403 & 0.3694 & 0.1266 & 0.1002 & 0.1117 & 0.0774 \\
\hline B_M_2 & 0.0185 & 0.0222 & 0.0078 & 0.0299 & 0.0322 & 0.0133 & 0.0119 & 0.0146 & 0.0067 \\
\hline B_M_3 & 0.0056 & 0.0067 & 0.0024 & 0.0103 & 0.0111 & 0.0044 & 0.0029 & 0.0034 & 0.0020 \\
\hline B_M_M & 0.0006 & 0.0007 & 0.0004 & 0.0010 & 0.0011 & 0.0007 & 0.0004 & 0.0004 & 0.0003 \\
\hline Car age & 3.7947 & 3.1251 & 5.7421 & 1.0251 & 0.9577 & 1.5201 & 5.4048 & 4.7926 & 6.6205 \\
\hline $\begin{array}{l}\text { Premium } \\
\text { discount }\end{array}$ & 0.6031 & 0.5535 & 0.7476 & 0.5011 & 0.4684 & 0.7412 & 0.6625 & 0.6189 & 0.7490 \\
\hline Observations & 104,191 & 77,534 & 26,657 & 38,304 & 33,713 & 4,591 & 65,887 & 43,821 & 22,066 \\
\hline
\end{tabular}

insurance claim settlements, the "accident $\neq$ claim" problem may not affect the result because it could simultaneously exist in clients seeking an independent agent and those seeking direct writer channels for their insurance. Based on these two points, the "accident without a claim" problem may not influence our results. ${ }^{15}$

Table 2 provides the mean analysis of variables for all policies issued by the insurer to its clients. This table indicates that the clients of independent agencies and direct underwriting systems are largely dissimilar with respect to the characteristics observed by the insurer. These differences are observed in claim probability, claim numbers, risk classification and bonus-malus coefficient variables. Moreover, car age may be an alternative factor dominating the selection of channels because newer car owners mostly depend on dealer-owned agents. Policyholders are further categorised into owners of cars aged three years or less, and owners of cars aged more than three years to examine the influence of car age. ${ }^{16}$

In testing the model of Venezia et al., focus is given on the correlation between marketing channel choice and accident claims. Table 2 shows the claim probability and claim numbers of the two marketing channels for the total samples and the two

${ }^{15}$ To observe whether those accidents without claim cases could cause potential biases, we omitted those claim cases with loss amounts less than NT\$5,000 or NT\$10,000 (US\$168 or US\$336, respectively) and reran the regressions. The findings are consistent with the results of the current version. Thus, the "accident $\neq$ claim" problem might not cause potential biases.

${ }^{16}$ We appreciate the referee's pointing out of the importance of separating whole samples into two subsamples according to car age. 
subsamples in 2008. With regard to the clients of independent agents, the average claim number was 0.0610 . Up to 5.37 per cent of 77,534 policyholders filed at least one claim. As to the clients of the direct underwriting system, the average claim number was 0.0546 , with 4.65 per cent of 26,657 policyholders filing at least one claim. Furthermore, channelclaim correlation is observed between the policyholders with cars aged three years or less and those policyholders with cars aged more than three years. Regarding policyholders with cars aged three years or less, data indicate that clients of independent agents have a near-claim probability with the clients of direct underwriters. Different results are shown for policyholders with cars aged more than three years. The clients of independent agents tend to file more accident insurance claims compared with clients of direct underwriters. This finding suggests the existence of a positive correlation between marketing channel choice and accident claims in Taiwan's automobile insurance market. Therefore, for this group, high-risk clients are more likely to choose independent agents for their insurance needs, whereas low-risk customers are attracted to the direct underwriting system.

\section{Methodology}

Venezia et al. provide a theoretical explanation for the co-existence of distribution systems and propose that high-risk clients are more likely to purchase insurance through independent agents, whereas low-risk customers prefer the direct underwriting system. Their study suggests that the incidence of claim filing by clients of independent agents is higher than the claim filing by clients of direct underwriters. To test this prediction, we adopt a testing procedure suggested by Dionne et al., ${ }^{17}$ who considered the nonlinear effect by employing two-stage regressions.

Using two-stage probit regressions to test the existence of asymmetric information problems in the automobile insurance market, we estimate the choice of marketing channel by probit regression in the first stage.

$$
\operatorname{Prob}\left(\text { channel }=1 \mid X_{i}\right)=\Phi\left(X_{i} \gamma\right),
$$

where $X_{i}$ is the initial exogenous variable, $\gamma$ is the vector of regression coefficient, and $\Phi$ is the density and cumulative distribution function of $N(0,1)$.

In the second stage, we regress the occurrence of claim filing by the following probit regression:

$$
\operatorname{Prob}(\operatorname{claim}=1)=\Phi\left(\text { channel } \beta_{1}+E(\text { channel }) \beta_{2}+X_{i} \gamma\right),
$$

where E(channel) is the estimator from the first stage model. We add the estimated expected choice of marketing channel E(channel) into Eq. (2) to take into account the nonlinear effects and test the channel-claim correlation. We expect coefficient $\beta_{1}$ to be positive, which means that the occurrence of claim filing by the clients of the independent agency system is higher than the direct underwriting system.

\footnotetext{
${ }^{17}$ Dionne et al. (2001).
} 
Table 3 Probit regression of third-party liability insurance on having a claim

\begin{tabular}{|c|c|c|c|c|c|c|}
\hline \multirow[t]{4}{*}{ Variables } & \multicolumn{6}{|c|}{ Dependent variable: Having a claim } \\
\hline & \multicolumn{2}{|c|}{ Model 1} & \multicolumn{2}{|c|}{ Model 2} & \multicolumn{2}{|c|}{ Model 3} \\
\hline & \multicolumn{2}{|c|}{ Total samples } & \multicolumn{2}{|c|}{ Car age $\leqslant 3$ years } & \multicolumn{2}{|c|}{ Car age $>3$ years } \\
\hline & Coefficient & p-value & Coefficient & p-value & Coefficient & $p$-value \\
\hline Intercept & $-2.1636^{* * *}$ & $<0.0001$ & $-2.7325 * * *$ & $<0.0001$ & 0.6602 & 0.7655 \\
\hline Channel & $0.0376^{* *}$ & 0.0155 & -0.0122 & 0.7196 & $0.0686^{* * *}$ & 0.0001 \\
\hline $\mathrm{E}($ channel) & 0.6637 & 0.2977 & $1.3201^{*}$ & 0.0573 & -3.9010 & 0.2754 \\
\hline Class_1 & -4.1623 & 0.9968 & -2.9409 & 0.9989 & -3.4535 & 0.9976 \\
\hline Class_2 & $1.0174 *$ & 0.0803 & 0.7421 & 0.3085 & $3.1722 *$ & 0.0511 \\
\hline Class_3 & $0.2264 *$ & 0.0872 & $0.2824 *$ & 0.0529 & -0.0492 & 0.8632 \\
\hline Class_4 & 0.0611 & 0.6262 & 0.1690 & 0.2794 & -0.5888 & 0.2178 \\
\hline Class_5 & 0.0846 & 0.1378 & -0.0282 & 0.6911 & 0.1175 & 0.3784 \\
\hline Class_6 & 0.0783 & 0.1114 & 0.0935 & 0.1634 & -0.1667 & 0.4876 \\
\hline Class_7 & -0.0049 & 0.9332 & -0.0259 & 0.6272 & 0.2976 & 0.1834 \\
\hline Class_9 & 0.0249 & 0.5230 & -0.0155 & 0.8519 & 0.0086 & 0.8582 \\
\hline Class_10 & -0.0197 & 0.6440 & 0.0363 & 0.6210 & $-0.1328^{*}$ & 0.0843 \\
\hline B_M_1 & 0.0035 & 0.9792 & -0.1219 & 0.2562 & $0.6985^{*}$ & 0.0777 \\
\hline B_M_2 & 0.1992 & 0.1788 & 0.0845 & 0.4713 & $1.1737^{*}$ & 0.0790 \\
\hline B_M_3 & 0.2428 & 0.1492 & 0.1018 & 0.4888 & $1.1571^{* *}$ & 0.0395 \\
\hline B_M_4 & $0.9211^{* * *}$ & $<0.0001$ & $0.9138 * * *$ & 0.0001 & $1.4333^{* * *}$ & 0.0049 \\
\hline Observations & \multicolumn{2}{|c|}{104,191} & \multicolumn{2}{|c|}{38,304} & \multicolumn{2}{|c|}{65,887} \\
\hline Log Likelihood & \multicolumn{2}{|c|}{-21130.22} & \multicolumn{2}{|c|}{-7810.80} & \multicolumn{2}{|c|}{-13280.05} \\
\hline
\end{tabular}

$* * *, * *$ and $*$ indicate significance at 1,5 and 10 per cent level, respectively.

\section{Empirical findings}

To test the screening mechanism hypothesis, we first employ the pricing factors as the control variables in the regressions. The testing results from Eq. (2) are shown in Table 3. According to this equation, the coefficient estimate associated with the marketing channel should be significantly positive. For the total samples, the estimation result of Model 1 shows a positive correlation between marketing channel choice and accident claims. The estimated value of $\beta_{1}$ has a positive value of 0.0376 , which is statistically significant at the 5 per cent level. Regarding policyholders with cars aged three years or less, the estimation results of Model 2 demonstrate that a negative coefficient estimate associated with the marketing channel $\beta_{1}$ has a negative value of -0.0122 , which is not statistically significant. However, for policyholders with cars aged more than three years, the estimated value of $\beta_{1}$ has a positive value of 0.0686 , which is statistically significant at the 1 per cent level. ${ }^{18}$ Therefore, for this group, the estimation results indicate strong evidence for asymmetric information when the marketing channel is used as a screening mechanism.

${ }^{18} \mathrm{We}$ also regressed a one-stage specification and obtained results similar to the two-stage regressions. The estimation coefficient ( $p$-value) of Models 1,2 and 3 are $0.0379(0.0147),-0.0078(0.8182)$ and $0.0687(0.0001)$, respectively. 
Table 4 Probit regressions on having a claim with additional classification variables

\begin{tabular}{|c|c|c|c|c|c|c|}
\hline \multirow[t]{4}{*}{ Variables } & \multicolumn{6}{|c|}{ Dependent variable: Having a claim } \\
\hline & \multicolumn{2}{|c|}{ Model 1} & \multicolumn{2}{|c|}{ Model 2} & \multicolumn{2}{|c|}{ Model 3} \\
\hline & \multicolumn{2}{|c|}{ Total samples } & \multicolumn{2}{|c|}{ Car age $\leqslant 3$ years } & \multicolumn{2}{|c|}{ Car age $>3$ years } \\
\hline & Coefficient & p-value & Coefficient & p-value & Coefficient & p-value \\
\hline Intercept & $-2.1374 * * *$ & $<0.0001$ & $-2.4072 * * *$ & $<0.0001$ & $-1.0566^{* * *}$ & 0.0006 \\
\hline Channel & $0.0755^{* * *}$ & $<0.0001$ & -0.0229 & 0.5146 & $0.1089 * * *$ & $<0.0001$ \\
\hline $\mathrm{E}($ channel) & $0.3052 * *$ & 0.0419 & $0.7695 * * *$ & 0.0050 & $-0.8371 * * *$ & 0.0062 \\
\hline Class_1 & -4.2027 & 0.9968 & -3.3860 & 0.9987 & -4.0096 & 0.9973 \\
\hline Class_2 & $1.0781^{*}$ & 0.0554 & 0.8142 & 0.2621 & $2.2612 * *$ & 0.0138 \\
\hline Class_3 & $0.3208 * * *$ & 0.0060 & $0.3271 * *$ & 0.0192 & 0.2457 & 0.2658 \\
\hline Class_4 & 0.0370 & 0.7538 & 0.1134 & 0.4602 & -0.1288 & 0.4965 \\
\hline Class_5 & $0.1461 * * *$ & 0.0007 & 0.0173 & 0.7812 & $0.3256 * * *$ & $<0.0001$ \\
\hline Class_6 & $0.0828^{*}$ & 0.0693 & 0.0578 & 0.3627 & 0.0502 & 0.4608 \\
\hline Class_7 & 0.0373 & 0.1080 & 0.0073 & 0.8179 & $0.2372 * * *$ & $<0.0001$ \\
\hline Class_9 & -0.0050 & 0.9050 & -0.0039 & 0.9607 & $0.1867 * * *$ & 0.0081 \\
\hline Class_10 & -0.0374 & 0.3773 & 0.0503 & 0.4853 & -0.0654 & 0.2163 \\
\hline B_M_1 & $0.1575^{* * *}$ & $<0.0001$ & 0.0273 & 0.4226 & $0.2878 * * *$ & $<0.0001$ \\
\hline B_M_2 & $0.3101 * * *$ & $<0.0001$ & $0.1303^{*}$ & 0.0729 & $0.7030 * * *$ & $<0.0001$ \\
\hline B_M_3 & $0.3879 * * *$ & $<0.0001$ & $0.1784^{*}$ & 0.0791 & $0.8001 * * *$ & $<0.0001$ \\
\hline B_M_4 & $1.0622 * * *$ & $<0.0001$ & $1.0041 * * *$ & $<0.0001$ & $1.0406 * * *$ & 0.0001 \\
\hline Car age & $0.0328 * * *$ & $<0.0001$ & 0.0335 & 0.1612 & -0.0235 & 0.1699 \\
\hline Premium discount & $0.0500^{*}$ & 0.0800 & $0.1198 * * *$ & 0.0005 & $-0.2411 * * *$ & 0.0022 \\
\hline Observations & \multicolumn{2}{|c|}{104,191} & \multicolumn{2}{|c|}{38,304} & \multicolumn{2}{|c|}{65,887} \\
\hline Log likelihood & \multicolumn{2}{|c|}{-21098.08} & \multicolumn{2}{|c|}{-7805.59} & \multicolumn{2}{|c|}{-13250.85} \\
\hline
\end{tabular}

$* * *, * *$ and $*$ indicate significance at 1,5 and 10 per cent level, respectively.

When pricing factors are employed as the control variables, the results reveal that a positive channel-claim correlation exists only in the subsample of owners of cars aged more than three years. However, additional variables that can affect the choice of marketing channel and the occurrence of risk should be considered. For instance, newer car owners tend to purchase their insurance from independent agents, and those owners who purchase their insurance from direct underwriters tend to get a discount on their premium. Therefore, we add the car age and premium discount variables into the models.

Models 1, 2 and 3, shown in Table 4, illustrate that the results yield consistent estimates of the coefficients when additional variables are added to the control variables. ${ }^{19}$ However, whether the positive correlation between marketing channel choice and risk merely reflects the effect of car age is uncertain. Based on the first-stage regression model, the result shows that car age is negatively correlated with the choice

${ }^{19}$ To obtain robustness results, we reran the regressions on the other insurance coverage combination (of NT\$1 million bodily injury coverage and NT\$0.3 million property damage coverage protection). The coefficients ( $p$-value) of the marketing channel in Models 1, 2 and 3 are $0.0771(0.0020), 0.0842(0.2438)$ and $0.0804(0.0026)$, respectively. 
of marketing channel. ${ }^{20}$ This finding supports the idea that newer car owners mostly rely on independent agents, whereas older car owners prefer to purchase insurance from direct underwriters. However, car age is not significantly correlated with the occurrence of risk in the second-stage regression results. ${ }^{21}$ Therefore, the positive relationship between risk and channel is not caused by car age. The results indicate that when policyholders tend to choose agents freely, high-risk policyholders prefer to purchase insurance from an independent agent, whereas lower-risk policyholders tend to buy insurance from a direct underwriter.

The results show that a positive channel-claim correlation exists only in the subsamples with owners of cars aged over three years. For the empirical results, Cohen ${ }^{22}$ provides a different interpretation for similar findings. She finds that a positive coverage-claim correlation exists only for experienced drivers; however, no such correlation exists for young drivers with less than three years of driving experience. She claims that such findings imply that "learning" plays an important role in the automobile insurance market. Thus, the learning effect in a market surrounded with asymmetric information can explain the empirical findings.

Empirical findings support the screening theory of Venezia et al. and indirectly provide evidence for the market imperfection hypothesis. Although cross-subsidisation (with complete information) could predict the same relationship observed in the empirical findings, the critical part of the empirical findings settles on the existence of asymmetric information, because conditional dependence is tested instead of unconditional dependence. However, the findings of the paper cannot exclude the possibility that asymmetric information and cross-subsidisation could co-exist in the market.

In addition, whether the positive channel-claim correlation can be regarded as evidence for the product quality hypothesis remains uncertain. According to the product quality hypothesis, independent agents are more effective in representing the interests of their clients because they can provide better ex-ante insurance claim consultation and ex-post claim coordination services to their customers. In other words, if independent agents can provide contracts with a higher quality of service than direct underwriters can, then the test of correlation between risk and marketing channel is equivalent to that between risk and coverage in terms of service quality. However, due to lack of claim service quality variables, this paper cannot directly examine whether independent agents provide a higher claim service quality to their customers than the one that the direct underwriters render. Thus, this result may support the asymmetric information hypothesis, but may not preclude the product quality hypothesis.

\section{Conclusion}

The current paper seeks to test the prediction of Venezia et al. and proposes two-stage regression procedures commonly used to test asymmetric information. The empirical

\footnotetext{
${ }^{20}$ Dependent variables: marketing channel choice; estimation coefficient ( $p$-value) of car age: $-0.1645(<0.0001)$.

${ }^{21}$ Dependent variables: having a claim; estimation coefficient ( $p$-value) of car age: $-0.0235(0.1699)$.

${ }^{22}$ Cohen (2005)
} 
results support the screening mechanism hypothesis proposed by Venezia et al. and demonstrate that marketing channel choice can serve as a screening mechanism in an insurance market under asymmetric information. However, the empirical findings of this paper cannot exclude the possibility that both the product quality and market imperfection hypotheses jointly determine the choice of agents of policyholders.

The lack of data raises two questions that deserve future study. First, this paper selects voluntary automobile third-party liability insurance in testing the screening mechanism hypothesis because policyholders who purchase additional voluntary automobile third-party insurance have a high demand for advantageous claim services from independent agents. However, policyholders may express greater concern over the services of repairing their own vehicles, which are covered by automobile damage insurance, rather than the service for the third party for which the policyholder is at fault. Thus, a study on automobile damage insurance, where current data are limited, will provide further contribution. Second, the positive channel-claim correlation may not necessarily imply that preference for good service is equivalent to high-risk clients. Low-risk clients similarly have the right to expect good service. If an independent agent can provide better claim services, such that high-risk clients tend to choose an independent agent for their insurance, the three dimensions, namely, channel selection, risk and service preference, could be examined simultaneously. However, due to lack of a suitable variable quantity of claim service preference, this problem cannot be fully analysed in the current paper. A future study on this topic could be fruitful.

\section{References}

Barrese, J., Doerpinghaus, H. and Nelson, J.M. (1995) 'Do independent agent insurers provide superior service? The insurance marketing puzzle', The Journal of Risk and Insurance 62(2): 297-308.

Barrese, J. and Nelson, J.M. (1992) 'Independent and exclusive agency insurers: A reexamination of the cost differential', The Journal of Risk and Insurance 59(3): 375-397.

Berger, A.W., Cummins, J.D. and Weiss, M.A. (1997) 'The coexistence of multiple distribution systems for financial services: The case of property-liability insurance', Journal of Business 70(4): 515-546.

Blair, R. and Herndon, J. (1994) 'A survivor test of the American agency system of distributing property liability insurance', The Journal of Economics of Business 1(2): 283-290.

Browne, M.J. (1992) 'Evidence of adverse selection in the individual health insurance', The Journal of Risk and Insurance 59(1): 13-33.

Browne, M.J. and Doerpinghaus, H.I. (1993) 'Information asymmetries and adverse selection in the market for individual medical expense insurance', The Journal of Risk and Insurance 60(2): 300-312.

Cawley, J. and Philipson, T.J. (1999) 'An empirical examination of information barriers to trade in insurance', The American Economic Review 89(4): 827-846.

Chiappori, P.-A. and Salanié, B. (2000) 'Testing for asymmetric information in insurance markets', The Journal of Political Economy 108(1): 56-78.

Cohen, A. (2005) 'Asymmetric information and learning: Evidence from the automobile insurance market', The Review of Economics and Statistics 87(2): 197-207.

Cummins, J.D. (1977) 'Economies of scale in independent insurance agencies', The Journal of Risk and Insurance 44(4): 539-553.

Cummins, J.D. and VanDerhei, J. (1979) 'A note on the relative efficiency of property-liability insurance distribution systems', Bell Journal of Economics 10(2): 709-719.

Dionne, G. and Gagné, R. (2002) 'Replacement cost endorsement and opportunistic fraud in automobile insurance', Journal of Risk and Uncertainty 24(3): 213-230. 
Dionne, G., Gouriéroux, C. and Vanasse, C. (2001) 'Testing for evidence of adverse selection in the automobile insurance market: A comment', Journal of Political Economy 109(2): 444-473.

Etgar, M. (1976) 'Service performance of insurance distributors', The Journal of Risk and Insurance 43(3): 487-499.

Finkelstein, A. and McGarry, K. (2006) 'Multiple dimensions of private information: evidence from the long-term care insurance market', The American Economic Review 96(4): 938-958.

Finkelstein, A. and Poterba, J. (2004) 'Adverse selection in insurance markets: Policyholder evidence from the U.K. annuity market', The Journal of Political Economy 112(1): 183-208.

Fong, W.M. (2002) 'On the cost of adverse selection in individual annuity markets: Evidence from Singapore', The Journal of Risk and Insurance 69(2): 193-207.

Haddad, G.K. and Anbaji, M.Z. (2010) 'Analysis of adverse selection and moral hazard in the health insurance market of Iran', The Geneva Papers on Risk and Insurance-Issues and Practice 35(4): 581-599.

Joskow, P.L. (1973) 'Cartels, competition and regulation in the property-liability insurance industry', Bell Journal of Economics and Management Science 4(2): 375-427.

Kim, H., Kim, D., Im, S. and Hardin, J.W. (2009) 'Evidence of asymmetric information in the automobile insurance market: Dichotomous versus multinomial measurement of insurance coverage', The Journal of Risk and Insurance 76(2): 343-366.

Kim, W.-J., Mayers, D. and Smith, C.W. (1996) 'On the choice of insurance distribution systems', The Journal of Risk and Insurance 63(2): 207-227.

Klumpes, P.J.M. (2004) 'Performance benchmarking in financial services: Evidence from the UK life insurance industry', Journal of Business 77(2): 257-273.

Klumpes, P.J.M. and Schuermann, S. (2011) 'Corporate, product and distribution strategies in the European life insurance industry', The Geneva Papers on Risk and Insurance-Issues and Practice 36(1): $50-75$.

Li, C.-S., Liu, C.-C. and Yeh, J.-H. (2007) 'The incentive effects of increasing per-claim deductible contracts in automobile insurance', The Journal of Risk and Insurance 74(2): 441-459.

Marvel, H. (1982) 'Exclusive dealing', Journal of Law and Economics 25(1): 1-25.

Mayers, D. and Smith, C.W. Jr. (1981) 'Contractual provisions, organizational structure, and conflict control in insurance markets', Journal of Business 54(3): 407-434.

Posey, L.L. and Tennyson, S. (1998) 'The coexistence of distribution systems under price search: Theory and some evidence from insurance', Journal of Economic Behavior \& Organization 35(1): 95-115.

Posey, L.L. and Yavas, A. (1995) 'A search model of marketing systems in property-liability insurance', The Journal of Risk and Insurance 62(4): 666-689.

Puelz, R. and Snow, A. (1994) 'Evidence on adverse selection: Equilibrium signaling and cross-subsidization in the insurance market', Journal of Political Economy 102(2): 236-257.

Regan, L. (1997) 'Vertical integration in the property-liability insurance industry: A transaction cost approach', The Journal of Risk and Insurance 64(1): 41-62.

Regan, L. and Tennyson, S. (1996) 'Agent discretion and the choice of insurance marketing system', Journal of Law and Economics 39(2): 637-666.

Regan, L. and Tzeng, L.Y. (1999) 'Organizational form in the property-liability insurance industry', The Journal of Risk and Insurance 66(2): 253-273.

Saito, K. (2006) 'Testing for asymmetric information in the automobile insurance market under rate regulation', The Journal of Risk and Insurance 73(2): 335-356.

Sass, T.B. and Gisser, M. (1989) 'Agency cost, firm size, and exclusive dealing', Journal of Law and Economics 32(2): 381-400.

Seog, S.H. (1999) 'The coexistence of distribution system when consumers are not informed', The Geneva Papers on Risks and Insurance Theory 24(2): 173-192.

Trigo-Gamarra, L. (2008) 'Reasons for the coexistence of different distribution channels: An empirical test for the German insurance market', The Geneva Papers on Risk and Insurance - Issues and Practice 33(3): 389-407.

Venezia, I., Galai, D. and Shapira, Z. (1999) 'Exclusive vs. independent agents: A separating equilibrium approach', Journal of Economic Behavior \& Organization 40(4): 443-456.

Wang, J.L., Chung, C.-F. and Tzeng, L.Y. (2008) 'An empirical analysis of the effects of increasing deductibles on moral hazard', The Journal of Risk and Insurance 75(3): 551-566. 


\section{About the Authors}

Shu-Hui Hsieh is a Senior Instructor in the Department of Insurance and Finance at National Taichung University of Science and Technology. She is also a PhD candidate at the College of Business at the Feng Chia University in Taiwan. Her major interests include risk management and insurance.

Chun-Ting Liu is an assistant professor in the Department of Insurance and Finance at National Taichung University of Science and Technology. His main research interests include insurance marketing and risk management.

Larry Y. Tzeng is a professor in the Finance Department at National Taiwan University in Taiwan. He currently serves as an associate editor of the Journal of Risk and Insurance and Risk Management and Insurance Review. 